\title{
BMG Global Health Persisting trend in the breach of medical neutrality: a wake-up call to the international community
}

\author{
Soumitra S Bhuyan, ${ }^{1}$ Ikenna Ebuenyi, ${ }^{2}$ Jay Bhatt ${ }^{3}$
}

To cite: Bhuyan SS,

Ebuenyi I, Bhatt J. Persisting trend in the breach of medical neutrality: a wakeup call

to the international community. BMJ Global Health 2016;1:e00109. doi:10.1136/bmjgh-2016000109

Received 12 October 2016 Accepted 18 October 2016

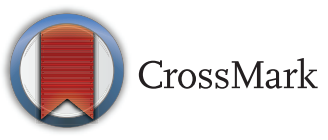

${ }^{1}$ Division of Health Systems Management and Policy, School of Public Health, The University of Memphis, Memphis, Tennessee, USA

${ }^{2}$ King's College London, and London School of Hygiene and Tropical Medicine, London, UK

${ }^{3}$ Health Research and Educational Trust, Chicago, Illinois, USA

Correspondence to Dr Soumitra S Bhuyan; sbhuyan@memphis.edu
History is dotted with stories of war crimes in which civilians, patients and health personnel have been killed and health facilities destroyed by warring factions. In 1949, the International Humanitarian Law (IHL) as contained in the four 1949 Geneva Conventions was officially ratified by 196 countries. ${ }^{1}$ The law promoted medical neutrality and non-interference with medical services for people in war zones. The breach of medical neutrality became regarded as war crime, due to its impact on civilians and the health personnel who have a duty to save lives and treat the wounded in and around war zones.

In time, the IHL, which has its roots on principles of humanity, impartiality and neutrality, have undergone modifications with the Additional Protocols in 1977 (to protect the victims of international and noninternational armed conflicts) and 2005 (to adopt the Red Crystal, in countries where the Red Cross and Red Crescent emblems may be objectionable). ${ }^{1}$ But over the years, war crimes have persisted with little or no definitive action by the international community to stem the tide. ${ }^{2}$ From the 1970 s, when facilities and human lives were destroyed in Mozambique to the 1990s in Chechnya, Thailand and El Salvador where similar acts were perpetrated. The destruction of health facilities in Syria, Iraq, Afghanistan and South Sudan has become a recurring issue requiring urgent action to salvage the lives of the wounded and endangered civilian populations, and the health workers in these locations who continue to stay at their job post in the face overwhelming reasons to run. ${ }^{34}$

The inhumane attacks on health facilities have in no way begun to calm down. According to data from the WHO, there have been 113 attacks in 17 countries in the first half of 2016. ${ }^{5}{ }^{6}$ As of 6 October 2016, 'Every hospital in eastern [Aleppo] has been hit at least once. One of the main trauma hospitals was hit 4 times in a 5-day period'. A 2015 WHO report stated that about 654 medical personnel had lost their lives since the onset of the war in Syria. ${ }^{8}$ Health workers and facilities continue to be targets of attack with the majority of the incidents under-reported. ${ }^{2}$ In another attack, a trauma centre in Kunduz, Afghanistan, was destroyed by the US air forces, leading to the death of 42 people. $^{9}$

Médecins Sans Frontières (MSF) has been working in South Sudan since 1983 and between 1993 and 2014, there have been about 50 violent attacks on health facilities that resulted in the harm and/or death of patients and health personnel. These targeted attacks on health services have led to displacement of patients and deprivation of the populace of the much-needed clinical services offered by MSF. Between June 2013 and December 2014, there were four violent attacks on MSF health facilities in South Sudan, which resulted in the death of 58 people on hospital grounds. These deaths include patients and non-medical staff and affect the most vulnerable population which includes women, children and the infirm. ${ }^{3}$ Since the first draft of this editorial in June 2016, the information and statistics on the attack on MSF facilities has been updated no fewer than four times to include additional events.

In 2013, sustained attack on health facilities resulted in the closure of an MSF hospital in Pibor town, South Sudan; thus depriving about 100000 inhabitants in the area of their only source of healthcare. ${ }^{3} \mathrm{~A}$ similar attack on Nasir, Upper Nile State, South Sudan, led to the closure of the MSF facility in the town which previously served a population of about 300000 and was the major source of surgical care for the wounded. ${ }^{4}$ The effect of these attacks is enormous. ${ }^{9} \quad 10$ Indeed, an undermined health system results in needless suffering, 
increase in morbidity and mortality and a breakdown in preventive care. What happens to the vaccination needs of children born in South Sudan, Syria or Afghanistan through this conflict? What of the implications for waterborne diseases or a disease like HIV? Table 1 outlines the WHO reported deaths and injuries by country in 2014 and $2015 .^{11}$

Although some health personnel continue to risk their lives in spite of the obvious dangers they face in war zones, their number continues to decline as most health professionals migrate to areas of safety. ${ }^{2}{ }^{3}$ The impact of this mass exodus of health professionals inevitably results in worsening health indices of the population. Attacks on health facilities and personnel affect the patients who live in fear of death in hospitals, and the psychological health of the populace that live through the violence. The association between trauma and violence and post-traumatic stress disorder and other psychological consequences is well documented. These present and long-term health implications need urgent attention from national governments and the international community.

Table 1 WHO reported deaths and injuries by country in 2014 and $2015^{11}$

\begin{tabular}{|c|c|c|c|}
\hline \multirow[b]{2}{*}{$\begin{array}{l}\text { Countries and } \\
\text { territories }\end{array}$} & \multicolumn{3}{|l|}{ 2014-2015 } \\
\hline & $\begin{array}{l}\text { Number of } \\
\text { attacks } \\
\text { recorded }\end{array}$ & $\begin{array}{l}\text { Total } \\
\text { deaths }\end{array}$ & $\begin{array}{l}\text { Total } \\
\text { injuries }\end{array}$ \\
\hline Afghanistan & 19 & 69 & 50 \\
\hline $\begin{array}{l}\text { Central African } \\
\text { Republic }\end{array}$ & 30 & 30 & 17 \\
\hline Colombia & 7 & 5 & 19 \\
\hline $\begin{array}{l}\text { Democratic Republic } \\
\text { of the Congo }\end{array}$ & 10 & 35 & 11 \\
\hline Guinea & 11 & 8 & 80 \\
\hline Iraq & 43 & 114 & 198 \\
\hline Liberia & 5 & 0 & 0 \\
\hline Libya & 33 & 55 & 65 \\
\hline Myanmar & 1 & 0 & 0 \\
\hline Nigeria & 10 & 23 & 20 \\
\hline Pakistan & 43 & 102 & 66 \\
\hline Sierra Leone & 3 & 2 & 10 \\
\hline Somalia & 6 & 11 & 6 \\
\hline South Sudan & 18 & 52 & 3 \\
\hline Sudan & 20 & 0 & 31 \\
\hline Syrian Arab Republic & 228 & 352 & 668 \\
\hline Ukraine & 32 & 17 & 28 \\
\hline $\begin{array}{l}\text { West Bank and Gaza } \\
\text { Strip }\end{array}$ & 53 & 14 & 188 \\
\hline Yemen & 22 & 70 & 101 \\
\hline Totals & 594 & 959 & 1561 \\
\hline
\end{tabular}

The IHL is explicit and provides for protection of patients, health facilities, health personnel and patients in times of war as long as they are not directly involved in hostilities. The international community needs to rise to the occasion and match action with words by mandating the United Nations Security Council to provide protection for health facilities in war zones and enter into dialogue with government and warring groups to respect the principles of medical neutrality in conflict areas. The United Nations Security Council and governments of all nations should adopt measures to integrate into the social system respect for medical neutrality and evolve means of punishing offenders to serve as a deterrent. Although it is often hard to legislate on behaviours, social education for the young and members of the armed forces in all nations is a strategy that may ensure respect for medical neutrality and observance of the Geneva Conventions.

Contributors SSB, IE and JB contributed to all stages of the study. Competing interests None declared.

Provenance and peer review Commissioned; internally peer reviewed.

Data sharing statement No additional data are available.

\section{REFERENCES}

1. International Committee of the Red Cross. Summary of the Geneva Conventions of 1949 and their additional protocols. http:// www.redcross.org/humanityinwar/summary-of-the-genevaconventions-of-1949-and-theiradditional-protocols (accessed 19 Jun 2016).

2. Heisler M, Baker E, McKay D. Attacks on health care in Syrianormalizing violations of medical neutrality? N Engl J Med 2015;373:2489-91.

3. South Sudan Conflict Violence Against Healthcare. http://www.msf. org/sites/msf.org/files/msf-south_sudan_conflictviolence_against healthcare.pdf (accessed 19 Jun 2016).

4. Human Rights Watch. Safe Guarding Health in Conflict. Attacks on Health Global Report. 2015. https://www.hrw.org/sites/default/files/ related material/HHR\%20Attacks\%200n\%20Hospitals\%20brochure $\% 200515 \% 20 L O W R E S . p d f$ (accessed 19 Jun 2016).

5. World Health Organization. Attacks on Health Care Dashboard: 2016 Quarter 1. http://www.who.int/hac/techguidance/attacks dashboard_2016_q1.pdf?ua=1 (accessed 6 Oct 2016).

6. World Health Organization. Attacks on Health Care Dashboard: 2016 Quarter 2. http://www.who.int/hac/techguidance/Attacks_ Dashboard_2016_Q2.pdf?ua=1 (accessed 6 Oct 2016).

7. World Health Organization. 6 October 2016. WHO Tweet. https:// twitter.com/WHO/status/784044979631038464 (accessed 6 Oct 2016).

8. Kourdi ME, Hume T. Kerry expresses outrage after 50 killed in strike on Syrian hospital. CNN. http://edition.cnn.com/2016/04/28/middleeast/syriaaleppo-hospitalairstrike/HospitalstargetedacrossSouth (accessed 19 Jun2016).

9. Starr B, Browne R. Pentagon: U.S. bombing of Afghanistan hospital not a 'war crime'. CNN. http://edition.cnn.com/2016/04/29/politics/ u-s-airstrike-hospitalafghanistan-investigation/ (accessed 19 Jun 2016).

10. Center for Public Health and Human Rights (CPHHR) Report. Syrian Medical Voices from the Ground: The Ordeal of Syria's Healthcare Professionals. 2015. https://www.samsusa.net/foundation/images/ PDFs/Syrian\%20Medical\%20Voices\%20from\%20the\%20Ground_F. pdf (accessed 19 Jun 2016).

11. World Health Organization. Report on Attacks on Health Care in Emergencies. 2016. http://www.who.int/hac/techguidance/ attacksreport.pdf (accessed 6 Oct 2016) 